\title{
Alguns apontamentos sobre as mudanças nas relações de Gênero no meio pentecostal
}

\author{
Otávio Barduzzi Rodrigues da Costa ${ }^{* 1}$
}

Resumo: A intenção deste artigo é mostrar as mudanças ocorridas no cenário Pentecostal Tradicional Brasileiro. Houve a preocupação em escrever acerca disso uma vez que os clássicos acerca do tema não mais alcançam as constantes mudanças pelas quais esse grupo religioso passou nos últimos cinco anos. Em especial as Assembleias de Deus, objeto desse estudo. Para ser mais especifico há de se mostrar aqui as mudanças diversas relacionadas aos costumes, teologia, ética e rituais que as Assembleias de Deus e algumas igrejas que se espelham nelas estão passando. A metodologia utilizada é a observação participante decorrente de mais de sete anos de pesquisa entre as Assembleias de Deus. Conclui-se que estão ocorrendo várias mudanças no que se refere as relações de gênero, rituais, teologias e costume dentro desse tipo de pertença religiosa. Aqui há de se enfocar as mudanças em relação ao gênero.

Palavras-chave: Pentecostalismo; Gênero e religião; mudanças sociais

Abstract: The intent of this article is show all the changes in the scenario of Brazilian Pentecostal orthodox Churches. There was concern in writing about it since the classics on the subject no longer reach the constant changes that this religious group spent the past five years. In particular the Assemblies of God, the object of this study. To be more specific here is to show the various changes related to customs,

Cientista social formado pela UNESP com ênfase em antropologia, Advogado (OAB-SP 314.526) formado pela ITE, mestre em filosofia pela UNESP, doutorando em ciências da Religião pela Universidade Metodista. É presbítero da Assembleia de Deus Missionária de Bauru-SP já a cerca de 8 anos. Professor de sociologia e filosofia da Universidade Metodista e do IFSP. 
theology, ethics and rituals that the Assemblies of God and some churches that mirror them are going through. The methodology used is participant observation due more than seven years of research among the Assemblies of God. We conclude that several changes are occurring regarding gender relations, rituals, theologies and custom within this type of religious affiliation. Here we will indicate the changes about gender relationship.

Keywords: Pentecostalism, gender and religion, social change

\section{Introdução}

A verdadeira religião é a vida que levamos, não o credo que professamos.

Louis Nizer

Estamos em época de mudanças sociais bem como crises, como um dos principais segmentos da sociedade, a religião também passa por mudanças (BERGER, 1971, p.21), pode-se afirmar que estamos em época de efervescência religiosa (CAMPOS, 2002 p.97). Sobretudo no Brasil, as profundas mudanças econômicas e sociais, bem como a inserção do país, de modo crescente no cenário econômico mundial afetou vários segmentos da sociedade brasileira e consequentemente sua religiosidade também foi afetada (MUNIZ DE SOUZA \& MARTINO, 2004, p.15).

Tratar de religião e gênero no Brasil é uma tarefa difícil, visto que de um lado existem aspectos de uma comunidade tradicional de valores centenários próprios; do outro de conquistas necessárias à promoção da igualdade de gênero. Mas impor a uma comunidade 
tradicional certas posições politicamente adequadas pode ferir um princípio de conservação dos costumes tradicionais. No entanto, não se pode aceitar certas posições machistas, sobretudo quando essas comunidades conseguem espaço político que afeta a todos. Esse trabalho então visa a apontar certas mudanças de mentalidade que estão surgindo dentro de uma comunidade tradicional, trata-se de um trabalho de uma mudança na história e cultura das Assembleias de Deus, é um trabalho sobre história e antropologia dessa religião e não sobre importantes conquistas dos direitos femininos.

Tradicionalmente a relação de gênero nas igrejas pentecostais em especial nas Assembleias de Deus (AD's) se caracteriza por uma leitura fundamentalista bíblica descrita em I Timóteo 2:11-12 "A mulher aprenda em silêncio, com toda a sujeição. Não permito, porém, que a mulher ensine, nem use de autoridade sobre o marido, mas que esteja em silêncio" e em $1^{\circ}$ Coríntios 14:34-35 "As mulheres estejam caladas nas igrejas, porque lhes não é permitido falar. E, se querem aprender alguma coisa, interroguem em casa a seus próprios maridos, porque é indecente que as mulheres falem na igreja", bem como outras passagens semelhantes, porém tais posições têm tido suas interpretações desprezadas ou seus efeitos minorados por essas comunidades, fenômeno que apresentaremos nesse trabalho. 
Não nos referimos aqui a alguma $\mathrm{AD}$ especifica, visto sua atual pluralidade e complexidade em variedade e costumes ${ }^{2}$, como esse trabalho vai mostrar, todas elas tem uma origem e algo em comum, a pluralidade de Assembleias de Deus, é parte integrante desse trabalho e das mudanças que ocorre nessa instituição plural e complexa aqui apontadas. Nossa experiência de observação participante segue a observação em um sem número em mais de 13 anos de conversão e observação dentro das assembleias de Deus dentro de todo o estado de São Paulo.

Faz-se necessária alguma ordem histórica e social para analisar os conceitos que se tratam no presente artigo. Usualmente classifica-se o pentecostalismo Brasileiro em três grandes fases (ou ondas). $\mathrm{O}$ pentecostalismo no Brasil tem sido classificado utilizando as ideias de Paul Freston, e se têm usado a periodização das três ondas. A primeira onda pentecostal registra a fundação e o surgimento da Congregação Cristã do Brasil e das Assembleias de Deus, nos moldes do pentecostalismo norte-americano e sueco de onde provinham os fundadores. A chamada segunda onda pentecostal teve origem na década de 1950, dava ênfase na glossolalia, na cura divina e nos milagres. São numerosas as denominações surgidas nessa época: Igreja

\footnotetext{
${ }^{2}$ Os estudiosos hoje falam em assembleias de Deus (no plural) isso porque há muita variabilidade entre elas, encontra-se, por exemplo, em relação ao costume de roupas algumas bem liberais, que admitem tatuagens cortes de roupa e cabelo moderno como a Assembleia de Deus do Brás e outras que não permitem nem que mulheres usem calças ou se depilem tal como o ministério Ipiranga.
} 
do Evangelho Quadrangular, antes conhecida como Cruzada Nacional de Evangelização (1953); Igreja Pentecostal "O Brasil para Cristo" (1956); Igreja Pentecostal "Deus é Amor" (1961); Metodista Wesleyana (1967) e muitas outras.

Na década de 70, uma terceira onda pentecostal, que é a mais estudada, por que usa grande espaço na mídia e suas ideias diferenciadas, com uma série de modificações da teologia pentecostal, deu início a formas de pentecostalismo conhecido com o nome de "pentecostalismo brasileiro" ou neopentecostalismo. A Igreja Universal do Reino de Deus (1977), a Igreja Internacional da Graça de Deus (1980), a Igreja Cristo Vive (1986), são expressões afirmadas do pentecostalismo brasileiro (MARIANO, 2005).

Cada uma focaliza seu discurso social e teológico em bases principais que podem até se misturar com as outras. Todas podem pregar, por exemplo, a cura, ou a prosperidade, mas cada uma enfoca algo que são diretrizes básicas da maioria das pregações em seus templos. A primeira onda (pentecostalismo) enfoca o batismo com o Espírito Santo e a glossolalia e a salvação da Alma (LEONARD, 1963 p. 47). A da segunda onda de (Deuteropentecostalismo) enfoca a cura divina e estimula cultos com excessiva demonstração de Glossolalia (MOREIRA, 1996 p.13). A da terceira (neopentecostalismo) exalta o exorcismo e mensagem da prosperidade (FERRARI, 2007 p.22). 
Números e características das igrejas Pentecostais.

Várias igrejas surgiram no cenário brasileiro nos últimos anos. Basta dar um pequeno passeio em qualquer bairro, sobretudo os periféricos, para ver um sem número de denominações religiosas das mais variadas ${ }^{3}$.

Os números demonstrados pelo Censo de 2010, divulgado recentemente pelo Instituto Brasileiro de Geografia e Estatística (IBGE) apontou que o número de evangélicos cresceu $61,45 \%$ no Brasil nos últimos dez anos. Apenas entre as Assembleias de Deus o crescimento foi estrondoso, mais de 48\%. Se utilizando de Dados do Censo 2010 (que calcula $\approx 13.000 .000$ - cerca de treze milhões de membros até 2009) e do órgão oficial de Notícias das Assembleias de Deus (doravante $\mathrm{AD}$ ), o CPADNews, que professa o número (feito por pesquisa própria através de registros das igrejas) anunciado da Convenção Geral das Assembleias de Deus o Brasil (CGADB) de 2012 de $\approx 25.000 .000$, chegamos a uma média de 18.000.000 (dezoito milhões) de membros, (CPADNews, 2012) o mesmo site observa que se

3 Existem muitas listas, sobretudo na WEB seguem sugestões de consulta: http://www.compulsivo.com.br/2010/02/todas-as-igrejas-do-brasil.html http://www.pulpitocristao.com/2010/05/confira-os-nomes-de-igrejas-mais-estranhose-engracados/ -

http://oskaras.com/97-nomes-estranhos-de-igrejas/

http://www.gospel10.com/igrejas/denominacao--batista--1

http://www.gospel10.com/igrejas/denominacao--igreja-pentecostal--18

http://www.mackenzie.br/10175.html 
a taxa de crescimento continuar constante, em 2020 o número de evangélicos da AD ultrapassará os 50.000.000. Sabe-se que o IBGE tem tido sua falhas de pesquisa (IGNÁCIO, 2010) (ROSEMBERG F. \& PIZA E. 1999), e parece essa falha aumentar nas pesquisas religiosas (OLIVEIRA \& SIMÕES, 2005), por isso adotar-se-á essa média.

As neopentecostais têm suas práticas pautadas pela teologia da prosperidade (Campos, 1996 p.521), que significa uma troca simbólica de promessas supostamente divinas de que os fiéis tem, em troca de sacrifícios financeiros, o direito-dever de se tornarem ricos e prósperos ${ }^{4}$.

Em que pese à popularidade alcançada, ou a grande colocação na mídia, não é nem de longe o maior representante do pentecostalismo no Brasil, perto das Assembleias de Deus (AD). Segundos dados do IBGE, as maiores representações somadas do neopentecostalismo não se aproximam das ADs que na menor das contagens chega a quinze milhões de membros. Todas as grandes igrejas midiáticas (IURD, IIGD, IPMD, Renascer, etc...) juntas não chegam a um terço das Assembleias de Deus (ADs).

Esses dados são importantes, embora escape um pouco do tema faz-se necessário para não confundir as igrejas que se está tratando para não confundir o neófito que quiçá leia o presente artigo.

\footnotetext{
${ }^{4}$ Uma análise aprofundada de seu discurso revela em sub tom, de que as pessoas que forem fieis em dízimos e ofertas tem não só o direito, mas o dever de serem prósperas (entenda-se ricas) e que em caso contrário deve existir algum pecado ou demônio atrapalhando a prosperidade dessa pessoa.
} 


\section{Mudanças diversas, presentes e vindouras. Diferenças de costume.}

As ADs e igrejas derivadas (que se originaram delas em sua formação, mas preservam vários pontos teológicos e sociológicos comuns) a que se denominará igrejas pentecostais ortodoxas, não estão isentas de mudanças diversas, que estão ocorrendo bem agora, sobretudo nos últimos 5 anos (de 2009 em diante). Vários eventos proporcionaram tais mudanças. A explosão Gospel ocorrida na década de 1990 (Cunha, 2007 p.9). A influência sempre histórica das igrejas norte-americanas, cujo discurso e teologia foram mudados após os acontecimentos de setembro de 2001. Outro em 2004 quando ocorre à saída da AD Madureira da CGADB. Também a ordenação de mulheres a partir de 2005. A crescente influência de Algumas ADs na mídia. Digno de nota é a mudança de discurso e sua grande influência teológica dos eventos promovidos pelos Gideões Missionários da Ultima Hora. Também vale lembrar a crescente influência teológica da CPAD e da CGADB, ou seja, há novas instituições influenciando as Igrejas pentecostais ortodoxas.

As ADs tradicionalmente são conhecidas por impor uma adequação moral aos seus membros no que se refere às vestimentas, impõe um jugo pesado inadequado ao clima brasileiro, tachando o que é ou não uma roupa decente. No seu livro o pastor Ricardo Gondim 
(2005, prefácio) ${ }^{5}$ denuncia o pesado jugo a qual estão dispostos tais pessoas. Essa é uma visão fundamentalista, mas que tem mudado, porém a muito ainda que mudar.

Para a maioria das ADs não se pode cortar cabelo para as mulheres e homens não podem ter cabelo comprido. De preferência o corte deve ser padronizado como o do pastor ou raspado, mulheres só podem usar saia comprida, no mínimo abaixo do joelho, homens podem andar de calça social e camisa, preferencialmente comprida, mas os obreiros no culto só podem portar terno e gravata, não importa o calor (ROLIM CARTAXO, 1987 p. 18). Mas hoje em dia algumas ADs tem mudado o padrão de vestimenta dentre outros costumes abaixo denunciados.

As assembleias de Deus depois de meados da década de 1940, tem se dividido em ministérios, que seguem mais ou menos a mesma matriz, aceitam os costumes umas das outras, convidam pregadores umas das outras para pregarem, mas estão divididas em ministérios a quais não tem, na prática, diferenças nos costumes, porém são feitos

\footnotetext{
${ }_{5}^{5}$ Criado e pastor da Assembleia de Deus por 15 anos, o pastor Ricardo Gondim com 50 anos de idade e vivencia dentro dessa igreja, observou muitas coisas nelas e depois abriu sua própria igreja (Igreja Evangélica Betesda) por não acreditar em certas regras e costumes impostos pela ADs.
} 
para beneficiar uma visão ${ }^{6}$ (poucos) ou uma família de líderes cuja liderança é passada de pai para filho (ALENCAR, 2005 p.102).

São inúmeros os ministérios, os mais numerosos são: Ministério Belém, Ministério Ipiranga, Assembleia de Deus Missionária, Assembleia de Deus Ministério Missão, filiadas a CGADB. Há inúmeras outras não filiadas tais como, AD Kairos, AD Restauração, AD Fama, etc... vale a pena registrar a Assembleia de Deus Madureira, que só perde para números de fiéis para a $\mathrm{AD}$ Belém, e tem sua própria convenção: $\mathrm{A}$ CONAMAD - A Convenção Nacional das Assembleias de Deus no Brasil do Ministério de Madureira.

Porém todas podem ser caracterizadas por certos códigos de comportamento que as caracteriza além da roupa: repetem em tom monocórdio versículos bíblicos, ao menos em tese não falam gírias e palavrões, evitam ouvir músicas mundanas e frequentar eventos mundanos. Não se pode: ver tevê, praticar esporte e cultuar ritmos musicais brasileiros, as crianças não podem brincar de futebol, bicicleta ou nadar, nem praticar esportes ou ir à praia. A justificativa é ao mesmo tempo simples e definitiva: são coisas do mundo ou do diabo ${ }^{7}$. Essa é uma visão fundamentalista bíblica que impunha certa interpretação de lideranças, mas que mudou nos últimos anos.

\footnotetext{
${ }^{6}$ Por exemplo, a AD missionária tem a visão de implantar missões em vários locais do Brasil e do mundo o vice-presidente ao contrário da maioria dos ministérios não é filho nem genro nem parente do presidente.

${ }^{7}$ Para alguns fiéis é a mesma coisa pois interpretam ao pé da letra a passagem bíblica descrita em 1Jo 5.19 "Sabemos que somos de Deus e que o mundo inteiro jaz no Maligno."
} 
Porém há mudanças, no segundo maior ministério ${ }^{8}$ das ADs. A Assembleia de Deus ministério Madureira tem mudado radicalmente seu costume. A veiculação anunciado por jornais gospel de todo o país confirma a facilmente verificável (basta ir a qualquer culto) a mudança às quais passam. Agora ficou muito mais visível e isso acaba ou acabara interferindo em outras assembleias de Deus, sob o risco de perder fieis:

No templo do Brás, porém, às $19 \mathrm{~h} 30$ do domingo 15 , um grupo de cerca de vinte fiéis fazia coreografias, ao lado do púlpito, ao som de uma batida funkeada. Seus componentes - mulheres maquiadas e com cabelos curtos tingidos, calça jeans justa e joias combinando com o salto alto; homens usando camiseta e exibindo corte de cabelo black power outrora sofreriam sanções, como uma expulsão, por conta de tais "ousadias". Mas ali eram ovacionados por uma plateia formada por gente vestida de forma parecida, bem informal. Palmas, também proibidas nas celebrações tradicionais, eram requisitadas pelo pastor Samuel de Castro Ferreira, líder do templo e um dos responsáveis por essa mudança de mentalidade (...)Sua Assembleia do "pode" tem agradado aos fiéis. "Meu pai não permitia que eu pintasse as unhas, raspasse os pelos ou cortasse o cabelo", conta a dona de casa Jussara da Silva, 49 anos. "Furei as orelhas só depois dos 40 anos. Faz pouco tempo, também, que faço luzes", afirma Raquel Monteiro Pedro, 47 anos, gerente administrativa. Devidamente maquiadas, as duas desfilavam seus cabelos curtos e tingidos adornados

\footnotetext{
${ }^{8}$ Ver mais detalhes na reportagem - Um pastor moderno entre os radicais jornal mídia gospel de 20 de novembro de 2011, disponível em http://www.midiagospel.com.br/variedades/noticias/assembleia-de-deus-sem-usos-ecostumes acessado em 12/dez/2012
} 
por joias pelo salão do Brás, cuja arquitetura, mais parecida com a de um anfiteatro, também se distingue das igrejas mais conservadoras.

Tais mudanças se encontram em franca aceitação pelos fiéis e afetam outras Assembleias de Deus e igrejas, que cada vez mais rompem com tradições, a AD do Bom Retiro com mais de 7.000 membros que pode ser citada como exemplo (Santos Correa, 2012 .p.56), mas a maioria das ADs ainda mantém seus costumes.

Especialmente frente à juventude das igrejas já há uma franca mudança de comportamento, tais como uso de camisetas (na maioria sempre se referindo a algo bíblico), uso de calça jeans e corte de cabelo (as mulheres ainda mantêm comprido, mas não mais até a cintura). Parte disso se deve também ao crescimento de grifes evangélicas que produzem roupas de cunho cristão, mas com corte moderno, atendendo a uma fatia do mercado antes inexplorada e agora em franca expansão (Cunha, 2007 p.47). Ainda na maioria das igrejas pentecostais tradicionais ou ortodoxas é obrigatório tanto fora como dentro da igreja o uso de roupas “decentes" (Se baseiam na Bíblia em $1^{\mathrm{a}}$ epistola a Timóteo 2:9), só que o que é decente tem sido mudado, a 40ª CGADB (Convenção Geral das Assembleias de Deus no Brasil), realizada em abril de 2012 em Cuiabá retificou o que é ou não decente (GCABD, 2012).

Essa mudança impacta a vestimenta que é reconhecida como a primeira impressão e expressão externa do que seria uma mulher 
pertencente ao movimento pentecostal (Campos Machado, 1996). A vestimenta do religioso pentecostal é fundamental para a constituição da sua identidade, e do reconhecimento pela sociedade em seu entorno, esse peso é maior para as mulheres ${ }^{9}$.

\section{Mudanças em relação ao gênero}

Embora nunca ordenadas, às mulheres e solteiros já tiveram nos anos 30 e 40 um papel importante nas ADs, porém o que ocorreu de 1940 até 1990 foi um conservadorismo extremado (Alencar, 2010 p. 76) que implicou em uma fase de machismo em franco declínio da década de 2000 para os dias de hoje.

Ultimamente tem se observado uma força maior da CGADB (Convenção Geral das Assembleias de Deus do Brasil) no que se refere às questões teológicas (por força de sua influência na CPAD e na produção das revistas de Escola dominical bem como na EETAD) e diminuindo sua força em questões de doutrina ${ }^{10}$. Isso se deve ao fato de multiplicar as denominações associadas sendo impossível unificar por enquanto a doutrina de cada igreja. Creio que se deve também a certo medo de sair da convenção como aconteceu com a AD Madureira. Em seu site oficial, ela é definida como "uma igreja evangélica pentecostal que prima pela ortodoxia doutrinária”.

\footnotetext{
${ }^{9}$ Idem.

${ }^{10}$ Logo será objeto de artigo próprio.
} 
Quanto à ordenação de mulheres, após anos de papel de submissão (MARIZ, 1994) e de incapacidade de ordenação (TOLEDO FRANCISCO, 2002), isso agora mudou; já é aceito desde que no dia 23 de abril de 2005, quando foi ordenada pastora a cantora gospel Cassiane, fato que entrou para a história da Assembleia de Deus. Foi consagrada a primeira pastora da denominação centenária, e indo contra a maioria do posicionamento da instituição ${ }^{11}$ : O pastoreado feminino quebrando um jejum de anos desde Linda Nyström, esposa de Samuel Nyström (ARAUJO, 2007. Verbete Mulheres) em 1919 na Amazônia. Vale registrar que já existem como ordenadas pastoras, a Elizete Malafaia, esposa de Silas Malafaia (o ministério de Silas Malafaia é independente com regras e costumes próprios) é um conhecido exemplo, dentre outras ordenações cada vez mais crescentes.

Porém não é unânime em todos os ministérios ${ }^{12}$, o que questiona a força das CGADB que reconheceu tais ordenações, mas ainda não se posicionou nem contra nem a favor da ordenação feminina (GOSPEL PRIME - 2011), porém certas mudanças em questão de gênero são claramente perceptíveis. $O$ que ocorre é que o posicionamento oficial da CGADB é contra o pastoreado feminino,

\footnotetext{
${ }^{11}$ Apesar de haver ordenação ainda há muita resistência, a resistência está centrada nas igrejas que ainda não tem pastoras ou não convidaram pastoras para pregar, após isso ocorrer a resistência pouco a pouco se dissolve (GOSPEL PRIME - 2011).

${ }^{12}$ Além de duas convenções regionais como a do distrito federal e do Mato Grosso, vários ministérios filiados a CGADB têm consagrado pastoras, podemos citar como exemplo a AD Missionária de Bauru - SP e a AD Torre Forte de S. J. do Rio PretoSP.
} 
porém suas afiliadas, as convenções regionais, já sagram pastoras e a CGADB fica então obrigada a reconhecer, pois está no seu estatuto o reconhecimento de sacerdotes (não diz o sexo) consagrado pelas convenções regionais (CGADB, estatuto artigo 17). Caso notório foi a sagração da Ex-senadora Marina Silva consagrada pela convenção do DF em abril de 2012 e na reunião da CGADB em maio já era apresentada como pastora no evento (GOSPEL MAIS - 2012).

A Convenção das Assembleias de Deus do Distrito Federal (CEADDIF -2011), cujo presidente é o Pr. Sóstenes Apolos reconheceu e sagra pastoras. Na Assembleia Geral Ordinária de setembro - Outubro de 2011, a CEADDIF aprovou o ingresso de mulheres como membros da convenção e a ordenação ao pastorado. A proposta foi aprovada pela maioria dos presentes. A CEADDIF é filiada a CGADB - Convenção Geral das Assembleias de Deus no Brasil, que não tem em seus quadros mulheres como membros, ou pelo menos não tinha até o momento. A CGADB não consagra ministros, quem o faz são as igrejas e o obreiro é reconhecido por seu pastor presidente, que apresentam listas para as Convenções regionais (como a CEADDIF), e após a ordenação, são encaminhadas fichas dos pastores (e das pastoras), para o devido registro junto a $\mathrm{CGADB}^{13}$.

Outra convenção regional a sagrar pastoras é a do Mato Grosso, CONADEMAT-14, que em 2011 consagrou a sua primeira pastora (CONADEMAT-14, 2011), por sinal mulher do pastor presidente da

\footnotetext{
${ }^{13}$ Idem.
} 
regional. Ao que parece, as mulheres dos pastores mesmo quando não consagradas às pastoras tem um papel preponderante na liderança do ministério feminino (MOTA, 2008).

O papel da CGADB ao contrário de outras igrejas tais como a batista, as presbiterianas têm pouca ou nenhuma influência sobre as congregações locais (SOUSA, 2011). Os pentecostais tradicionais em geral não tem uma convenção firme como as tradicionais ou uma instituição que interfira diretamente sobre sua teologia, simplesmente há rompimento da igreja local (por parte da igreja) que discorde das decisões. Em 2001 saiu uma portaria que negava a ordenação de mulheres, mas em 2009 um recurso administrativo baseado no art. 17 do estatuto da CGADB, (que omitia o sexo em reconhecimento de sacerdotes) fez reconhecer alguns casos específicos de ordenação de mulheres. Esse reconhecimento tem vários motivos, mas a apontamos a busca pela influência política das igrejas evangélicas e o papel que as mulheres evangélicas têm conseguido na política (DUARTE, 2009) tem levado os líderes da CGADB a rever seus conceitos. Duarte (2009) cita os casos emblemáticos de mulheres evangélicas, sobretudo assembleiana e suas conquistas na política tal como Marina Silva, Benedita da Silva dentre outras na conquista do poder político. 


\section{Machismo tradicional}

Ainda há certo machismo, sempre tradicional nas ADs (Mariz, 1994 p.12), esse machismo é inclusive aceito pela maioria das mulheres, que se põe em papel de submissão visto que há o entendimento geral, entre os homens e a maioria das mulheres de que a Bíblia diz assim (Campos Machado, 1996 p.199). Esse machismo se manifesta de várias maneiras, desde a aceitação geral de que não poderia haver mulheres pastoras, como a ideia de que mulher não trabalha, e que quem sustenta a casa é o homem (IDEM). Porém essa visão tem mudado vários pastores (em que pese o machismo na prática de suas vidas pessoais diárias), dizem em seus discursos e pregações que é grande o papel das mulheres no movimento pentecostal, esse entendimento é compactuado em anos de observação e também na Bíblia de Estudo Pentecostal (1995) nos comentários de provérbios 31.10-31, como no Dicionário de movimento Pentecostal (ARAUJO, 2007, verbete mulheres). Não há já algum tempo a separação de homens e mulheres nas igrejas da ADs (salvo em várias congregações pequenas do interior do país e ainda persiste essa pratica no ministério Ipiranga), ainda continuam a praticá-la a Congregação Cristã do Brasil e a IPDA. Nesse caso as mulheres sentam todas juntas do lado esquerdo do púlpito e os homens do lado direito para lembrar que elas são responsáveis pelo pecado original, segundo relato de pertencentes dessas comunidades. 
Sempre reconhecem a importância da mulher, mas as relegam ao serviço social e de oração da igreja. Algo pouco relatado é o preconceito que as mulheres têm delas mesmas, é observado pelas próprias mulheres que mulheres que trabalham fora, "não estão na visão", e que o "certo seria não trabalhar". Porém com a emancipação recente da mulher e a crescente conquista dos seus direitos esse preconceito tem diminuído, ainda mais porque houve a percepção de que família em que a mulher trabalhava aumentava a arrecadação do dizimo. Os cultos ultimamente têm dado grande importância para as mulheres e são homenageadas e chamadas para vários outros trabalhos na igreja ${ }^{14}$. Pode ser ou não por interesse, mas a mulher tem sido mais valorizada.

\section{Divórcio e casamento.}

Quanto à moral sobre o casamento ainda é soberano o fato de se manter a família, quase que a qualquer custo $^{15}$, sabe-se que o pentecostalismo tem uma visão machista (MARIZ, 1994 p.192), e o divórcio não era aceito pelas ADs, porém o preconceito com mulheres

\footnotetext{
${ }^{14}$ Por exemplo, a esposa do autor consagrada a diaconisa, como é publicitária e designer é constantemente procurada para fazer a arte dos cartazes de campanhas e outros serviços.

${ }^{15}$ Mesmo em caso de traição e agressão familiar há o estímulo para que o membro vítima perdoe o outro e haja reconciliação de casal, o ministério de casal tem sido um dos mais poderosos das igrejas.
} 
separadas antes de serem convertidas já inexiste, e está diminuído o preconceito com mulheres separadas antes da sua conversão ${ }^{16}$, porém estas são estimuladas a perdoar e continuar com seus maridos. O divórcio antes impensável hoje é possível apenas na possibilidade de adultério, e mesmo assim a pessoa deve ser "tratada espiritualmente" antes de se relacionar de novo com alguém. O que antigamente era impossível. Ainda é um assunto tabu e desafio para a igreja (STRECK, 2007 p.32), porém o poder da mulher dentro da igreja tem aumentado e proporcionalmente a isso o apoio e diminuição de preconceito ao divórcio também (FONSECA; MARIN; NASCIMENTO DE FARIAS, 2010 p.28).

Os pentecostais tradicionais demonizavam a televisão até ocorrer dois fatores: a influência e o sucesso dos televangelistas nos anos 1970. Há de se considerar o crescente acesso econômico para a televisão, ficava fácil demonizar algo que não tinha acesso, desde 1990 ficou permitido à televisão para ver desde que se evitassem programas de nudez ou indecentes, estimulando apenas aos programas religiosos e telejornais.

\footnotetext{
${ }^{16}$ Há pouco preconceito com homem separado ou divorciado, tanto é que há vários pastores consagrados que são separados, porém todos passam por "tratamento espiritual" nesse caso, que pode ser alguns anos ou meses sem pregar, estando no Banco sendo orientado por um pastor e tendo um grupo de intercessores orando por ele (a).
} 
Hoje, em face desses fenômenos, é permitida a televisão, tanto que ocorre a boca miúda o seguinte exemplo de testemunho: o Assembleiano antigamente dando testemunhos (oportunidades para que as pessoas que não são pregadores falem das suas experiências religiosas.) no púlpito - "irmãos, Jesus me salvou e já vendi a televisão"; já o Assembleiano hoje dando testemunhos - "irmãos, Jesus me abençoou e já comprei três televisores". Já rádio, especialmente programas evangélicos foi permitido, mas só após ampla discussão na década de 1940 (Alencar, 2010 p. 72).

Evidentemente, o maior acesso à mídia, a televisão introduziu novas ideias antes impensáveis as irmãs, tal como acesso a moda, ideários de beleza, que embora manipuláveis por uma indústria cultural de interesses escusos deu novas escolhas as pertencentes às assembleias de Deus em sua autoimagem (Mira, 2003 p. 40), além do mais o acesso ao computador e a internet, trouxe tremenda possibilidade de comunicação informacional ao mundo pentecostal (CAMPOS JR., 2012 p. 14), no que se refere à opressão tradicionalmente machista da AD's trouxe uma liberdade de trocas de ideias e conversas para as crentes femininas antes impossível e restrita ao seu círculo de amizade.

Trouxe diversas ideias antes totalmente alienadas além do padrão de beleza, trouxe também a ideia de introdução no mercado de trabalho e ideários de independência financeira trazida pelo capitalismo. Hoje a assembleiana segue certos costumes de beleza apresentado na 
mídia televisiva, comentam a novela e de como a protagonista estava vestida.

\section{Teologia da prosperidade $X$ teologia da salvação.}

A teologia da prosperidade também influencia as relações de gênero, portanto fazem-se necessários breves considerações sobre a mesma. A prosperidade para Assembleia de Deus é uma visão bem diferente das neopentecostais. Essas seguem a teologia ou evangelho da prosperidade que teve suas origens nos EUA, por volta dos anos 30 e 40 (Mariano, 1999, p. 151). No Brasil, segundo Mariano (op. Cit, p. 157), a Teologia da Prosperidade iniciou a sua trajetória nos anos 70, penetrando em muitas igrejas e ministérios, em especial: Internacional da Graça, Universal, Renascer em Cristo, Sara Nossa Terra, Nova Vida, Bíblica da Paz, Verbo da Vida, Cristo Salva, Cristo Vive, Nacional do Senhor Jesus Cristo. Cada uma delas deu de diferentes maneiras e de diferentes modos às doutrinas desse evangelho da prosperidade que se baseava em escritos de Hagin tais como: "Não ore mais por dinheiro [...] Exija tudo o que precisar." (HAGIN, p. 17 apud ROMEIRO, 1998, p. 43, grifos nossos). A Teologia da Prosperidade encontrou terreno fértil no Brasil há partir os anos 70, encontrando espaço nos grupos evangélicos pentecostais. Após certo tempo os pentecostais verdadeiros começaram a rejeitá-lo (PIERATT, 1993 p.81) o que ocasionou para quem acreditava uma ampla difusão de novas igrejas e divisões que 
acreditavam nesse tipo de evangelho. Surgiu daí as chamadas igrejas neopentecostais.

A prosperidade para os assembleianos não significam ter vários carros, belas casas, ter um alto salário, ou uma vida com fartura de bens materiais como é pregada pelas igrejas neopentecostais, e sim paz harmonia e segurança, em várias pregações é constante a definição "prosperidade é viver bem com aquilo que Deus permite que você viva". Ou seja, é um ato continuo de gratidão a Deus pelo que você tem não uma luta para conquistar coisas que o fiel ainda não tem.

Isso gera um verdadeiro conflito para o fiel, porque ele ouve num dia desses grandes pregadores, seja ao vivo ou na rádio, a teologia da prosperidade, mas na sua igreja, também assembleiana, o pastor alerta para o cuidado das falsidades da teologia da prosperidade. $\mathrm{Na}$ bíblia de estudo pentecostal (CPAD - 1995), no estudo "Riqueza e Pobreza" observa-se a seguinte afirmação: "o crente não deve se preocupar com acúmulos materiais nem amontoar bens... para o cristão as verdadeiras riquezas são o amor e fé...”. O que ocorre é que certos germes da teologia da prosperidade tem entrado entre os pentecostais tradicionais fazendo com que muitos creiam nisso, o que pode explicar o crescimento tanto da ADs, que estão aceitando tais mensagens, mas não com ponto central da sua teologia que ainda é a salvação das almas.

Simplesmente as igrejas pentecostais ortodoxas estão sofrendo influência de outras pentecostais, tais como as neopentecostais e deutero- pentecostais. Assim há diversas e inúmeras mudanças no que 
chamamos de pentecostais ortodoxos inclusive nas relações de gênero. Aos poucos a teologia da prosperidade tem chegado aos pentecostais ortodoxos, se por um lado aliena e escraviza os seus fiéis, e segue uma rígida lógica de mercado (CAMPOS, 1999) por outro possibilita uma coisa no que se refere ao gênero, induz a mulher a procurar e se inserir no mercado do trabalho. Antes a mulher que era relegada as tarefas do lar era o modelo a ser seguido, porém agora o modelo é a da mulher formada, empresaria e principalmente dizimista na Igreja.

A mulher antes relegada nos discurso ao papel de dona de casa, agora é estimulada em diversas pregações a trabalhar, a se tornar empresaria, de certo modo uma melhora na mentalidade, não motivada pelos ideais de libertação e autonomia da mulher, mas sim pelo dinheiro que essa pode trazer como dizimista.

\section{Considerações finais}

Como pode se notar as igrejas pentecostais a que se classificam aqui de pentecostais ortodoxas, especialmente as Assembleias de Deus, passam por profundas mudanças em seus direcionamentos morais e teológicos. O mundo está passando por grandes mudanças em todas as áreas. Mudanças há sempre na história, mas a intensidade do momento é única.

A mídia também muda o modo de com a igreja se relaciona com o seu fiel e vice versa. Santos Correa (2012, p.87) afirma: "A 
relação que é criada através da mídia social, oferece exatamente a associação que se busca no espaço público", assim o fiel antes negado no espaço público pela discrepância econômica, o encontra na igreja, na mídia social em vários espaços, este começa a aparecer e a gostar disso, o sentimento de humildade cristão vai sumindo, e criando novas relações sociais dentro do grupo religioso que muda cada vez mais as Igrejas.

Note-se que é a mensagem da teologia da prosperidade e da estrutura organizacional da Igreja, a conversão do mercado religioso, os fiéis e como a religião influencia cada vez mais mudanças em uma causalidade circular. É o surgimento de uma comunidade religiosa, que é de consumo de bens, e de um sentido de pertença, onde há uma reunião simbólica de interesses a partir de um encurtamento da distância através da mídia em influenciar suas teologias e práticas tradicionais mesmo entre os pentecostais ortodoxos. Aliado a isso, há um medo da perda de fieis por parte da liderança da Igreja, esses então permitem certas mudanças que devem ser cuidadosamente a estudadas, a fim de direcionar o estudo do campo religioso brasileiro atual.

É necessário um novo estudo religioso e a constante observação participante para manter atualizados os estudos dessas religiões que preocupam cada vez mais pela sua crescente influência na política e economia. 
Não vamos dizer que já há uma total independência da mulher, aliás independência é um conceito contraio na tradição pentecostal seja para homem seja para mulher. Porém já alguns passos têm sido dados e isso é motivo para se observar um avanço nas relações de gênero nessa pertença religiosa. Claro que ainda existem as AD's que mantém o seu tradicionalismo machista (ex. as AD's ministério Ipiranga que ainda mantém homens e mulheres em lados opostos da igreja), mas isto deve mudar com a constante influência apontada nesse trabalho.

\section{Referências}

ALENCAR, Gedeon F. (2005). Protestantismo tupiniquim: hipóteses da (não) contribuição evangélica à cultura brasileira. São Paulo: Arte Editorial.

ALENCAR, Gedeon F. de. (2010). Pentecostalismo Hitech: uma janela aberta, algumas portas fechadas. História Agora, São Paulo, v. 1 (Religiões e Religiosidades), p. 428-453, fev. 2010.

ARAUJO, Isael.(2007). Dicionário do movimento pentecostal. Rio de Janeiro: CPAD.

BERGER, Peter. (1971). La Religion dans la Conscience Moderne. Essai d'analyse culturelle, Paris. Centurion Paris, Ed. Sociales.

BÍBLIA português. (1995). Bíblia de Estudo Pentecostal.Trad. João Ferreira de Almeida. Edição rev. e corrigida. Rio de Janeiro - RJ : CPAD

BORELLI, V.. (2010). Mídia e religião: entre o mundo da fé e o do fiel. Rio de Janeiro, RJ: EPapers. 
CAMPOS JR, Luis de Castro; (1995). Pentecostalismo: sentido da palavra divina. São Paulo, SP: Editora Ática.

CAMPOS, Leonildo Silveira. (1996). Protestantismo Histórico e Pentecostalismo no Brasil: Aproximações e Conflitos. In:

GUTIERREZ, B.; CAMPOS, L. S. (Editores). (1996). Na força do espírito: o pentecostalismo na América Latina: um desafio às igrejas históricas. SP: Associação Literária Pendão Real.

CAMPOS, Leonildo Silveira. (1999). Teatro, templo e mercado. Petrópolis: Vozes.

CAMPOS, Leonildo Silveira. (2002). As mutações do campo religioso. In: Caminhando, vol. 7, n. 1 [9], p. 97-109 [Edição on-line, 2009] disponível em: http://www.sumarios.org/sites/default/files/pdfs/34368_4381.PDF acesso em 06/dez/2012

CAMPOS, Leonildo Silveira. (2005). As origens norte-americanas do pentecostalismo brasileiro: observações sobre uma relação ainda pouco avaliada. REVISTA USP, São Paulo, n.67, p. 100-115, setembro/novembro

CAMPOS MACHADO, Maria das Dores. (1996). Carismáticos e pentecostais, Adesão Religiosa na Esfera Familiar, Revista Brasileira de Ciências Sociais (RBCS) da ANPOCS, Rev. bras. Ci. Soc. v. 09. n. 36 São Paulo. Fev.

CONADEMAT-14 (2011) Convenção Regional das Assembleias de Deus do Mato Grosso - Ata de reunião anual de 2011 da CONADEMAT-14, reunião ocorrida em 15/05/2011.

CGADB,Convenção geral das Assembleias de Deus no Brasil (2012) resoluções $C G A D B$ - $40^{a}$ reunião da $C G A D B$ - Resoluções disponível em http://cgadb.org.br/home5a/fotos1/, acesso em 13/dez/2012. 
CONTINS, Marcia \& GOMES, Edlaine de Campos. (2008). Autencidades e edificações religiosas: comparando carismáticos católicos e neopentecostais. Revista Anthropológicas. Recife, UFP.

CONDE, Emílio. (2011). História das Assembleias de Deus no Brasil, Rio de Janeiro- RJ: CPAD.

CPAD -lições bíblicas - estudo sobre a verdadeira prosperidade. Outdez 2011 Comentários bíblicos de pastor Leonardo Bibiano. Autoria de lições CPAD.

CPADNews (2012) Jornal das casas publicadoras das Assembleias de Deus - números da AD. Brasil não será mais católico. publicado em 02/07/2012. disponível em: http://www.cpadnews.com.br/integra.php? $\mathrm{s}=25 \& \mathrm{i}=13601-$ acesso em 06/dez/2012,

CUNHA, Magali do Nascimento. (2007). A explosão Gospel, um olhar das ciências humanas sobre o cenário evangélico no Brasil, RJ-RJ, Mauad editora.

DUARTE, Tatiane dos Santos. (2009). "A autoridade não vem do sexo, mas sim do Senhor": Investidura religiosa e delegação política, anais da XXV - ANPUH - XXV SIMPÓSIO NACIONAL DE HISTÓRIA Fortaleza.

EETAD (2000a) Homilética. Falando de Deus aos homens. CPAD, Campinas -SP.

FERRARI, O.A. . (2007). A Igreja Universal do Reino de Deus e o exercício do poder. São Paulo, SP: Ave-Maria.

FONSECA, André Dioney; MARIN, Jérri Roberto; NASCIMENTO DE FARIAS, Marcilene. (2010). Relações de gênero e cultura religiosa: um estudo comparado sobre a atuação feminina na igreja evangélica luterana do Brasil e Assembleia de Deus. REVISTA DE HISTÓRIA COMPARADA, revista do programa de pós graduação em História Religiosa e das Religiões Rio de Janeiro, 4-1: 6-41. 
FRESTON, Paul, Breve história do pentecostalismo brasileiro. In: ANTONIAZZI, Alberto et al.. (1994). Nem anjos, nem demônios: interpretações sociológicas do pentecostalismo, Petrópolis, Vozes.

GONDIM, Ricardo. (2005). É proibido-O que a Bíblia permite e a igreja proíbe. Editora Mundo Cristão - São Paulo-SP.

GOSPELPRIME - jornal de notícias evangélicas (2011), AD no distrito federal ordena mulheres como pastoras - publicado em 04/2011 disponível em: http://noticias.gospelprime.com.br/assembleia-de-deusdistrito-federal-pastoras-mulheres/, acesso em 10/dez/2012.

GOSPELMAIS - jornal de notícias evangélicas (2012). Ex. senadora Marina Silva é ordenada pastora em Convenção das Assembleias de Deus do Distrito Federal- Publicado por Tiago Chagas em 16 de abril de 2012, disponível em: http://noticias.gospelmais.com.br/marina-silvaordenada-pastora-convencao-assembleias-deus-33250.html, acesso em 10/jan/2014.

HAGIN, Kenneth E. (1998). O Toque de Midas, t. Original The Midas Touch - Traduzido por Natan Rufino, São Paulo-SP, RHEMA Brasil Publicações.

IBGE-2010, Dados estatísticos sobre religião no Brasil, ftp://ftp.ibge.gov.br/Censos/Censo_Demografico_2010/Caracteristicas_ Gerais_Religiao_Deficiencia/tab1_4.pdf,

LEONARD, Emilie G. (1963). Protestantismo Brasileiro, São Paulo, Aste. 1963.

MATOS, Aldari Souza de. (2006). O movimento pentecostal: reflexões a propósito do seu primeiro centenário. Fides Reformata, São Paulo, Ano 11, n. 2, p. 23-50.

MARIANO, R. (1999). Neopentecostais: sociologia do novo pentecostalismo no Brasil. São Paulo, SP: Loyola. 
MARIANO, Ricardo. (2004). Expansão pentecostal no Brasil: o caso da Igreja Universal. Estudos Avançados de religião. vol.18, n.52, pp. 121138. ISSN 0103-4014.2004

MARIZ, Cecília. (1994). Alcoolismo, Gênero e Pentecostalismo. Religião \& Sociedade, Rio de Janeiro, v. 16, n.03, p. 80-93.

MIRA, Maria Celeste. (2003). "O masculino e o feminino nas narrativas da cultura de massas ou o deslocamento do olhar." Cadernos Pagu (21), Campinas-SP, Núcleo de Estudos de Gênero Pagu/Unicamp, pp. 13-38.

MOREIRA, A.. (1996). Novas igrejas e movimentos religiosos: $O$ pentecostalismo autônomo. Cadernos do IFAN, 15, 7-58.

MOTA, Elba Fernanda Marques, (2008) O feminino pentecostal: uma análise da revista "Círculo de Oração" da Igreja Assembléia de Deus. Anais do X Simpósio ABHR / UNESP - Assis - 12 a 15 de maio de 2008, disponível em: http://www.abhr.org.br/wpcontent/uploads/2008/12/mota-elba.pdf, acesso em 18/01/2014

MUNIZ DE SOUZA, Beatriz; MARTINO, Luís Mauro Sá. (2004). Sociologia da religião e mudança social-Católicos, protestantes e novos movimentos religiosos no Brasil, São Paulo - SP Paulus.

PIERATT, Alan B.. (1993). O evangelho da prosperidade: análise e resposta. São Paulo: Edições Vida Nova.

PRANDI, C.; GIOVANNI, Filoramo. (1999). As ciências das religiões. Paulus.

REVISTA ENFOQUE GOSPEL, (2011) $R$. $R$. Soares e seu ministério, revista independente de noticiais do evangelho, Rio de Janeiro, Ed. Edição 82 - MAI / 2011, disponível em: http://www.revistaenfoque.com.br/index.php?edicao $=82$ \&materia $=1067$ acesso em 05/dez/2012. 
ROLIM CARTAXO, Francisco. (1987). O Que É Pentecostalismo, Editora Brasilense, São Paulo, SP, .

ROMEIRO, Paulo. (1995). Super Crentes. O Evangelho segundo Kenneth Hagin, Valnice Milhomens e os Profetas da Prosperidade. São Paulo: Mundo Cristão, 1995.

SANTOS CORREA, Marina Aparecida Oliveira dos. (2012). Análise dos ministérios da igreja assembleia de Deus e a sua lógica de funcionamento, Tese de doutorado em ciências da Religião, PUC-SP, orientador, Dr. João Décio Passos. data da defesa. 11/abr/2012.

SANCHIS, Pierre. (2001). Religiões, Religião... Alguns Problemas do Sincretismo no Campo Religioso Brasileiro, in Pierre Sanchis (org.). Fiéis \& Cidadãos - Percursos de Sincretismo no Brasil. Rio de Janeiro, Eduerj.

SOUSA, Bertone de Oliveira.(2011). Uma perspectiva histórica sobre construções de identidades religiosas: A Assembleia de Deus em Imperatriz, MA. Maranhão: Ética Editora.

STRECK, Valburga Schmiedt. (2007). Famílias em transição: desafios para a sociedade e Igreja, Estudos Teológicos, v. 47, n. 1, p. 25-42, 2007 Revista de pós Graduação da UNICSUL, da Escola Superior de Teologia (EST), em São Leopoldo, RS. Disponível em: http://www3.est.edu.br/publicacoes/estudos_teologicos/vol4701_2007/e t2007-1b_vstreck.pdf, acesso em 05/dez/2012.

TOLEDO FRANCISCO, Crislaine Valeria de. (2002). Passagens híbridas: relações de gênero e pentecostalismo. Faculdade de Filosofia, Letras e Ciências Humanas da USP- tese de mestrado em sociologia, Defesa em 2002-08-16 São Paulo,2002, Orientador: Negrao, Lisias Nogueira.

IGNÁCIO, Sérgio Aparecido. (2010) Importância da Estatística para o Processo de Conhecimento e Tomada de Decisão SECRETARIA DE 
ESTADO DO PLANEJAMENTO E COORDENAÇÃO GERAL DO ESTADO DO PARANÁ disponível em http://www.ipardes.gov.br/biblioteca/docs/NT_06_importancia _estatistica_tomada_decisao.pdf acesso em 13/jan/2014.

ROSEMBERG F. \& PIZA E. (1998-99). A Classificação de 'Cor' na Pesquisa do IBGE. REVISTA USP, São Paulo, n.40, p. 122-137, dezembro/fevereiro 1998-99.

OLIVEIRA, Luiz Antonio Pinto de \& SIMOES, Celso Cardoso da Silva. (2005) O IBGE e as pesquisas populacionais. Rev. bras. estud. popul. [online]. 2005, vol.22, n.2, pp. 291-302. ISSN 0102-3098. http://dx.doi.org/10.1590/S0102-30982005000200007. 